\title{
Carbon-13 Solid State NMR Techniques to Evaluate the Morphology of $\mathrm{PP} / \mathrm{TiO}_{2}$ Composites
}

\author{
Igor Lopes Soares ${ }^{1}$, Maria Inês Bruno Tavares', André Luis B. B. e Silva ${ }^{2,3}$, \\ Antonio Gabriel Malagueta Feio ${ }^{3}$ \\ ${ }^{1}$ Instituto de Macromoléculas, Universidade Federal do Rio de Janeiro, Rio de Janeiro, Brazil \\ ${ }^{2}$ Instituto Federal do Mato Grosso, IFMT, Mato Grosso, Brazil \\ ${ }^{3}$ CENIMAT/I3N, Departamento de Ciência dos Materiais, Faculdade de Ciências e Tecnologia, Universidade \\ Nova de Lisboa, Caparica, Portugal \\ Email: Igorl@ima.ufrj.br
}

Received 22 October 2015; accepted 26 January 2016; published 29 January 2016

Copyright (C) 2016 by authors and Scientific Research Publishing Inc.

This work is licensed under the Creative Commons Attribution International License (CC BY). http://creativecommons.org/licenses/by/4.0/

\section{(c) (i) Open Access}

\section{Abstract}

Solid state NMR was successfully used to determine the proton spin-lattice relaxation time in the rotating frame $\left(\mathrm{T}_{1} \rho \mathrm{H}\right)$ for systems based on polypropylene (PP) and PP with titanium dioxide $\left(\mathrm{TiO}_{2}\right)$ organically modified or unmodified incorporated, in order to understand the molecular behavior of these systems. These techniques were employed in the samples organically modified and unmodified $\mathrm{TiO}_{2}$ to investigate the effect of organic modification on the dispersion and distribution of the particles in the PP matrix. The results were analyzed in terms of the effect of the particles organic modified or not according to the intermolecular interaction in the composites. According to the $T_{1} \rho H$ values, all composites showed at least two domains: the short values were related to the rigid part, which included the crystalline and amorphous phase constricted in it, while the longer times were attributed to the amorphous region, which had higher molecular mobility compared to the rigid region of the materials. The increase in the relaxation time parameter in the composites compared to the pure PP was associated to the strong interaction between titanium dioxide particles and the polymer chains. This effect was more pronounced for the systems containing organically modified $\mathrm{TiO}_{2}$. According to the results, it could be inferred that intermolecular interaction occurred in the $\mathrm{CH}_{2}$ and $\mathrm{CH}$ groups, being more intense with $\mathrm{CH}_{2}$ groups. Finally, the solid state NMR techniques were able to evaluate the molecular dynamics of those systems.

\section{Keywords}

NMR, PP, $\mathrm{TiO}_{2}$, Composites 


\section{Introduction}

Solid-state nuclear magnetic resonance is a non-destructive spectroscopy and it comprises many techniques and also permits us to analyze several nucleuses that contain different information on materials, especially polymer and their derivative materials [1]-[5]. Carbon-13 is an important nucleus that gives many responses on polymer chemical structure, arrangements, configurational and is specific to evaluate the molecular dynamics of polymers and materials based on it [6]-[11]. According to this statement, in this work, we have chosen to use the solid-state carbon-13 NMR spectroscopy as a tool to evaluate the systems formed by PP and titanium oxide modified or not, in order to obtain response on the molecular interaction between polymer and particles and also the way that the particles are dispersed and distributed.

The combination of solid state carbon-13 NMR techniques such as: magic angle $\left({ }^{13} \mathrm{C}\right.$ MAS $)$; spinning cross polarization magic angle spinning $\left({ }^{13} \mathrm{C}\right.$ CPMAS) and variable contact time (VCT) together with the measurement of proton spin-lattice relaxation time in the rotating frame, with a time constant $\mathrm{T}_{1} \rho$, will give many important information on polymer systems about intermolecular interactions and particles dispersion and distribution. The spin-lattice relaxation in the rotating frame can be determined through the decay of the resolved carbons during the variable contact time experiment under spin-lock conditions that generate a rotating magnetic field near the resonant frequency perpendicular to the static magnetic field [12]-[18].

The hydrogen MAS also is an important technique to help the evaluation of chains molecular dynamics and together with the carbon-13 NMR responses allow to understand the behavior of polymer systems [19] [20].

The first objective of this work is preparing $\mathrm{PP} / \mathrm{TiO}_{2}$ composites and nanocomposites using $\mathrm{TiO}_{2}$ with or without organic surface modification with hexylamine, seeking materials with characteristics of photodegradation or photostabilization. The second main objective is to use the combination of solid-state nuclear magnetic resonance techniques as a tool to evaluate the $\mathrm{PP} / \mathrm{TiO}_{2}$ systems, in their forms, according to the particles dispersion, distribution and their influence on polymer systems organization and morphology.

\section{Experimental}

\subsection{Sample Preparations}

The $\mathrm{PP} / \mathrm{TiO}_{2}$ composites and nanocomposites were initially prepared by physical mixing of the polymer and particles in a Tepron mixer at a rotation speed of $5 \mathrm{rpm}$ for $30 \mathrm{~min}$, using different $\mathrm{TiO}_{2}$ particle concentrations: $0.25 \%(\mathrm{w} / \mathrm{w}), 0.50 \%(\mathrm{w} / \mathrm{w}), 0.75 \%(\mathrm{w} / \mathrm{w}), 1.0 \%(\mathrm{w} / \mathrm{w})$. Modified and unmodified $\mathrm{TiO}_{2}$ particles were used to assess the influence of the chemical modification in the compatibility of polymer and particle, to disperse and distribute them in the polymer matrix. The sample codes are listed in Table 1 . The composites and nanocomposites were prepared by the melt method in a single-screw extruder (AX Plásticos model AX 1626) with L/D ratio of 26 and screw diameter of $16 \mathrm{~mm}$, containing three heating zones, coupled to a traditional bath and pelletizer. The processing parameters were temperatures of $160^{\circ} \mathrm{C}, 170^{\circ} \mathrm{C}$ and $190^{\circ} \mathrm{C}$, referring to the feed, compression and homogenization zones, respectively, rotation of $40 \mathrm{rpm}$ and pelletizing rate of $19 \%$. The matrix used was the conventional type for production of pellets. The pure PP was prepared in the same way to provide a standard for comparison with the nanocomposites obtained [21].

\subsection{Characterization}

\subsubsection{Differential Scanning Calorimetry (DSC)}

The DSC curves of the samples were obtained under $\mathrm{N}_{2}$, calibrated with an indium standard. The analysis

Table 1. $\mathrm{T}_{1} \mathrm{H}$ values for $\mathrm{TiO}_{2}, \mathrm{TiO}_{2}$ modified with propionic acid and $\mathrm{TiO}_{2}$ modified with propionic acid and octadecyl amine.

\begin{tabular}{cc}
\hline Samples & $\mathrm{T}_{1} \mathrm{H}$ \\
\hline $\mathrm{TiO}_{2}$ & 14 \\
$\mathrm{TiO}_{2}$ modified with propionic acid & 12 \\
$\mathrm{TiO}_{2}$ modified with octadecyl amine & 11 \\
\hline
\end{tabular}


involved a first heating from $10^{\circ} \mathrm{C}$ to $200^{\circ} \mathrm{C}$ followed by fast cooling $\left(100^{\circ} \mathrm{C} / \mathrm{min}\right)$, followed by another heating cycle of $20^{\circ} \mathrm{C} / \mathrm{min}$, from $20^{\circ} \mathrm{C}$ to $240^{\circ} \mathrm{C}$.

\subsubsection{X-Ray Diffraction (XRD)}

X-ray analyses were done in a Rigaku D/Max 2400 diffractometer, with nickel-filtered CuK $\alpha$ radiation of wavelength $1.54 \AA$, at room temperature. The $2 \theta$ scanning range varied from $2^{\circ}$ to $30^{\circ}$, with $0.05^{\circ}$ steps, operating at $40 \mathrm{KV}$ and $30 \mathrm{~mA}$.

\subsubsection{Nuclear Magnetic Resonance Spectroscopy (NMR)}

The NMR acquirements were obtained using a Bruker 300AVANCE NMR spectrometer, operating at $75 \mathrm{MHz}$ for carbons detection and $300 \mathrm{MHz}$ for proton detection. Protonspectra were obtained by accumulating $8 \mathrm{~K}$ data points over a spectral width of $4400 \mathrm{~Hz}$, using a $7.0 \mu \mathrm{s}$, 90 pulse with a recycle delay of $4 \mathrm{~s}$ between acquisitions. ${ }^{13} \mathrm{C}$ NMR, spectra were obtained with accumulation of $32 \mathrm{~K}$ data points covering a spectral width of $22000 \mathrm{~Hz}$, and a $5 \mu$ s, 90 pulse.

\section{Results and Discussion}

\subsection{DSC}

Based on DSC results, the melting temperatures (Tm) and the crystalline temperature (Tc) of the studied PP systems were determined to evaluate the possible changes in their values related to PP. The values of these thermal parameters for pure PP were $161^{\circ} \mathrm{C}$ and $121^{\circ} \mathrm{C}$, respectively. Analyzing the materials prepared with PP and $\mathrm{TiO}_{2}$ modified or not, the thermal parameters of the polymer matrix did not change, which is an indication that the particles did not influence processing stability and no degradation was detected.

\subsection{XRD}

Figure 1 exhibits the X-ray diffratograms of $\mathrm{TiO}_{2}$, unmodified particle and particle modified with propionic acid and octadecyl amine.

The crystallinity degree of the materials containing unmodified $\mathrm{TiO}_{2}$ did not change significantly, in a while for the materials prepared with organically modified $\mathrm{TiO}_{2}$ changes, it increases for the samples containing $0.25 \%$ of organic modification and for the others proportions does not change significantly. We believe that the small proportion of organically modified $\mathrm{TiO}_{2}$ could act as a nucleant particles, being nuclei for the matrix growth.

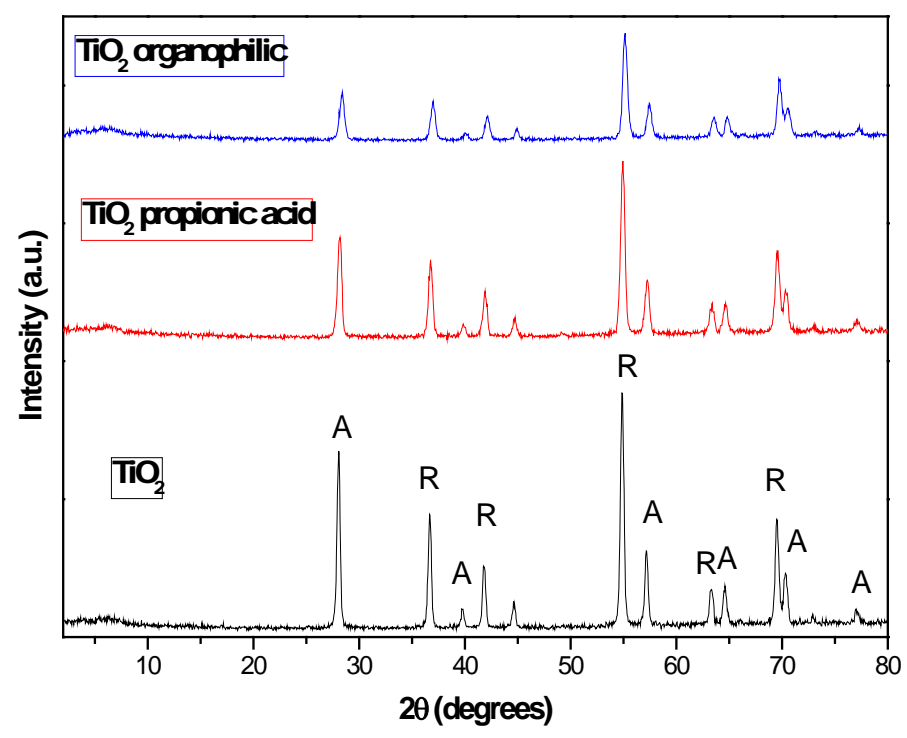

Figure 1. X-ray diffractogram of $\mathrm{TiO}_{2}$, unmodified particle and particle modified with propionic acid and octadecyl amine. 


\subsection{NMR}

Organically modified and unmodified $\mathrm{TiO}_{2}$ nanoparticles were used to investigate the effect of organic modification on their dispersion and distribution in the $\mathrm{PP}$ matrix. The molecular dynamic behavior of the $\mathrm{PP} / \mathrm{TiO}_{2}$ composites gives information on the microstructure of the composites. The NMR results were analyzed in terms of the effect of the organic modification of the particles and the intermolecular interactions within the composites.

Table 1 listed the $\mathrm{T}_{1} \mathrm{H}$ values for $\mathrm{TiO}_{2}, \mathrm{TiO}_{2}$ modified with propionic acid and $\mathrm{TiO}_{2}$ modified with propionic acid and octadecyl amine (C-18).

The proton spin-lattice relaxation time values presented the same behavior than $\mathrm{X}$-ray and thermal degradation temperature.

The behavior of $\mathrm{T}_{1} \rho \mathrm{H}$ for $\mathrm{CH}_{2}$ and $\mathrm{CH}_{3}$ group for all samples is shown in Figure 2, while that Figure 3 and Figure 4 shown the behavior of $\mathrm{T}_{1} \rho \mathrm{H}$ decay for $\mathrm{CH}_{2}$ and $\mathrm{CH}_{3}$ groups as function of $\mathrm{B} 1$ strength for sample PPm0.5\% and for sample PPN1\%, respectively.

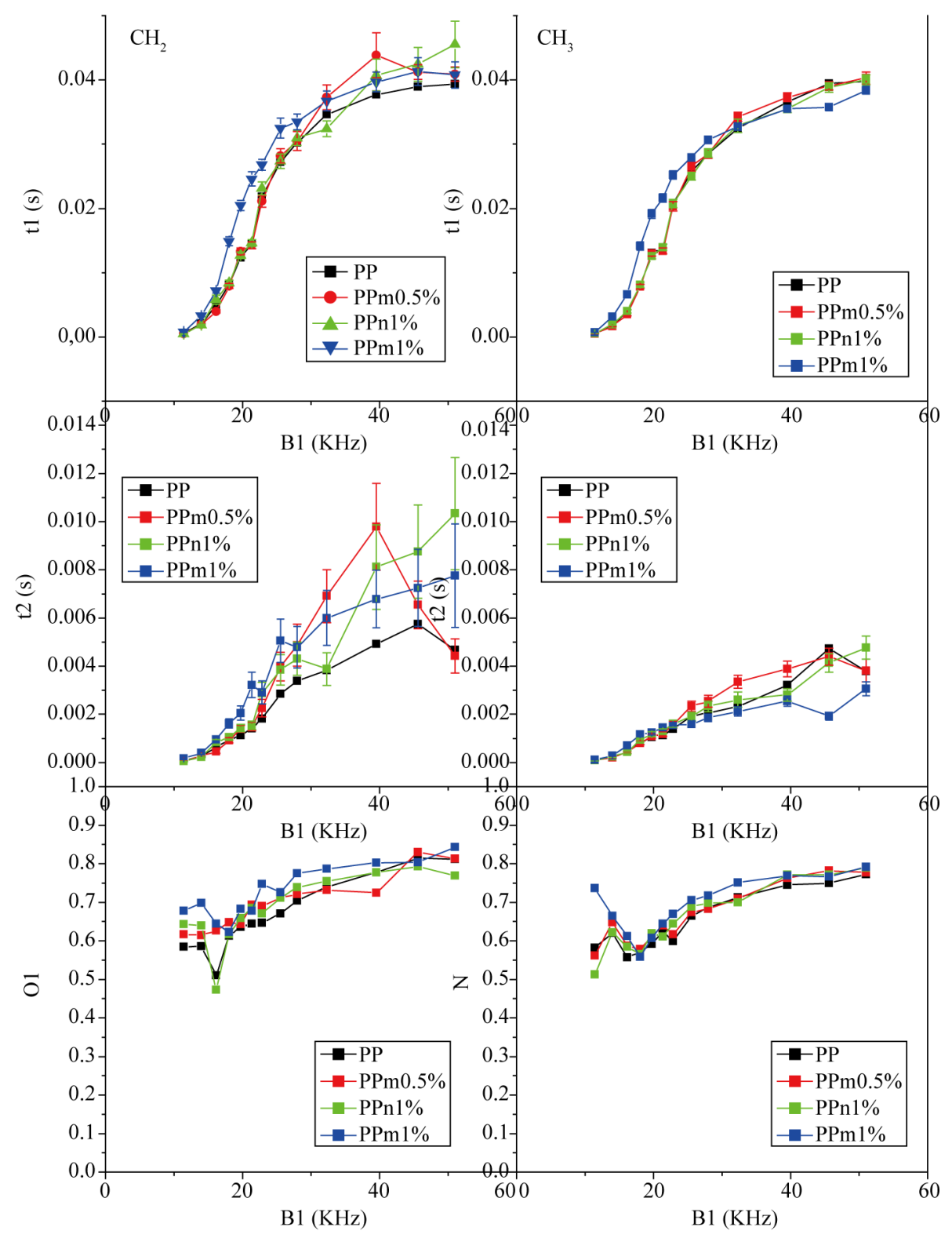

Figure 2. $\mathrm{T}_{1} \rho \mathrm{H}$ behavior for $\mathrm{CH}_{2}$ and $\mathrm{CH}_{3}$ group for all samples. 

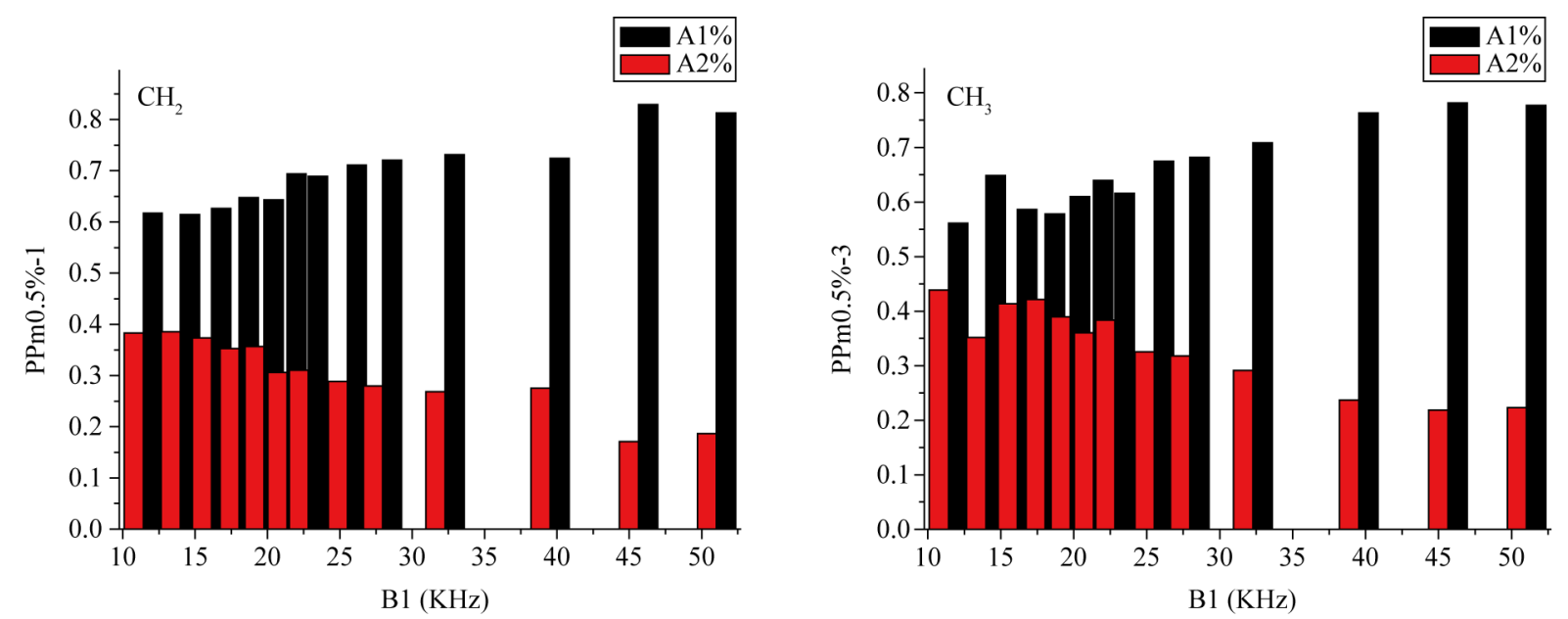

Figure 3. The behavior of $\mathrm{T}_{1} \rho \mathrm{H}$ decay for $\mathrm{CH}_{2}$ and $\mathrm{CH}_{3}$ groups as function of $\mathrm{B} 1$ strength for sample $\mathrm{PPm} 0.5 \%$.
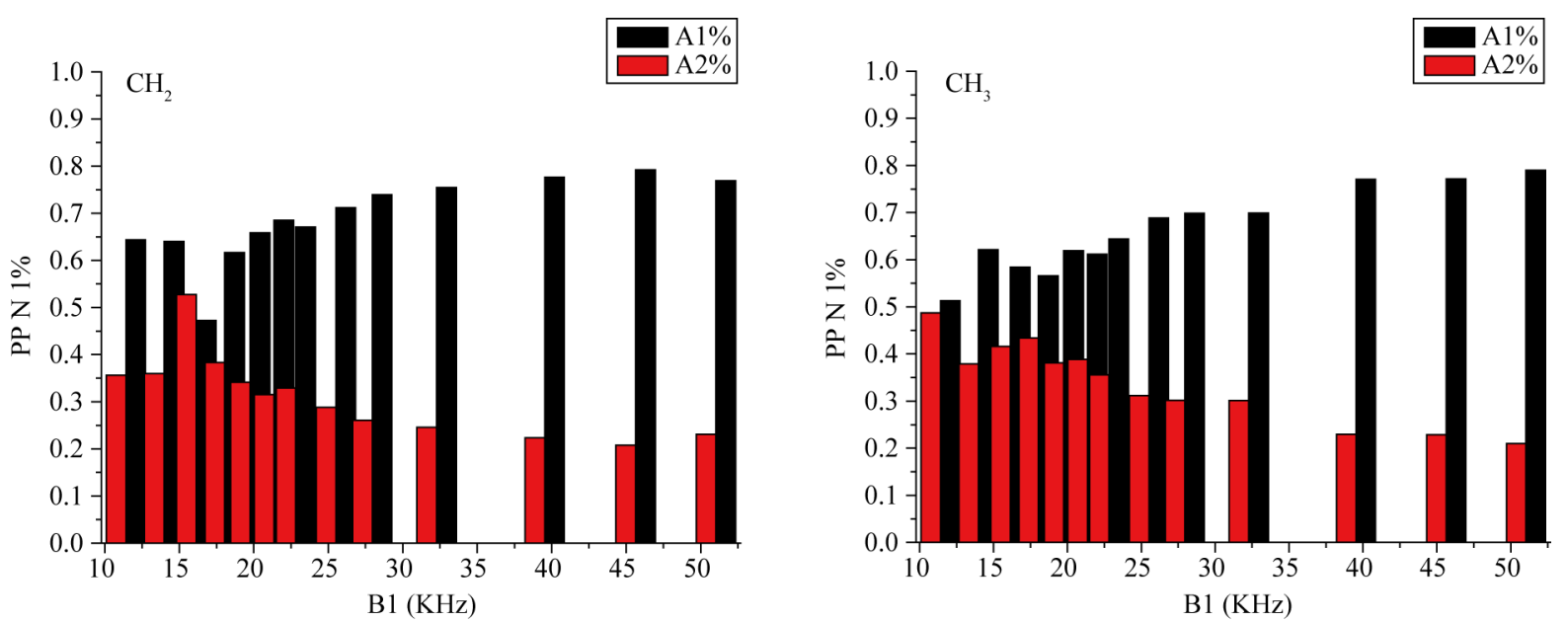

Figure 4. The behavior of $\mathrm{T}_{1} \rho \mathrm{H}$ decay for $\mathrm{CH}_{2}$ and $\mathrm{CH}_{3}$ groups as function of $\mathrm{B} 1$ strength for sample PPN1\%.

According to the measured $\mathrm{T}_{1} \rho \mathrm{H}$ values, all composites showed at least two dynamic domains: the short values were related to the rigid part of the system, which includes the crystalline and the highly constrained amorphous phase, while the longer relaxation times were attributed to the less constrained amorphous region, which has higher molecular mobility compared to the rigid region of the materials.

For all systems, the dispersion and distribution of the particles in the polymer matrix was detected. The increase in the relaxation time parameter in the composites compared to the pure PP was associated to the strong interaction between titanium dioxide particles and the polymer chains. This effect was more pronounced for the systems containing organically modified.

The increase of relaxation times values in the composite materials compared to the pure PP was associated to the strong interaction between titanium dioxide nanoparticles and the polymer chains. This effect was more pronounced for the systems containing organically modified $\mathrm{TiO}_{2}$.

\section{Conclusions}

$\mathrm{TiO}_{2}$ particles were organically modified; these treatments promoted an improvement in the interaction and consequently the dispersion of this nanoparticle in the polymer system. Thus, the best $\mathrm{PP} / \mathrm{TiO}_{2}$ sample contained with $0.50 \%$ of modified particles.

According to all results, it could be inferred that intermolecular interactions occurred mainly with $\mathrm{CH}_{2}$ and $\mathrm{CH}$ groups, being more intense with $\mathrm{CH}_{2}$ groups. 
Finally, the solid state high resolution NMR techniques were able to evaluate the proton resolved molecular dynamics of those systems.

\section{Acknowledgements}

The authors thank you the CAPES, CNPQ and FAPERJ for all financial support of this work and for the scholarship.

\section{References}

[1] Abragam, A. (1996) Principles of Nuclear Magnetism. Oxford Science Publications, Oxford.

[2] Chandrakumar, N. and Subramanian, S. (1987) Modern Techniques in High-Resolution FT-NMR. Springer-Verlag, New York, 388. http://dx.doi.org/10.1007/978-1-4612-4626-8

[3] Gil, V.M.S. and Geraldes, C.F.G.C. (1987) Ressonância Magnética Nuclear: Fundamentos, Métodos e Aplicações. Fundação Calouste Gulbenkian, Lisboa, 1012.

[4] Slichter, C.P. (1990) Principles of Magnetic Resonance. Springer-Verlag, New York, 665. http://dx.doi.org/10.1007/978-3-662-09441-9

[5] Stejskal, E.O. and Memory, J.D. (1994) High Resolution NMR in the Solid State., New York, 189.

[6] Bovey, F.A. and Mirau, P.A. (1996) NMR of Polymers. Academic Press.

[7] Koenig, J.L. (1992) Spectroscopy of Polymer. American Chemical Society, Washington, 328.

[8] Komoroski, R.A. (1986) High Resolution NMR Spectroscopy of Synthetic Polymers in Bulk. Methods in Stereochemical Analysis, 7, 379.

[9] Lyerla, J.R. and Yannoni, C.S. (1983) High-Resolution Carbon-13 NMR of Polymers in the Solid State. IBM Journal of Research and Development, 27, 302-312. http://dx.doi.org/10.1147/rd.274.0302

[10] Schmidt-Rohr, K. and Spiess, H.W. (1994) Multidimensional Solid-State NMR and Polymers. 1st Edition, Vol. 1, Academic Press, London, 478.

[11] Silvestri, R.L. and Koenig, J.L. (1993) Applications of Nuclear Magnetic Resonance Spectrometry to Solid Polymers. Analytica Chimica Acta, 283, 997-1005. http://dx.doi.org/10.1016/0003-2670(93)80261-I

[12] Berns, A.E. and Conte, P. (2011) Effect of Ramp Size and Sample Spinning Speed on CPMAS 13C NMR Spectra of Soil Organic Matter. Organic Geochemistry, 42, 926-935. http://dx.doi.org/10.1016/j.orggeochem.2011.03.022

[13] Silva, N.M., Tavares, M.I.B. and Stejskal, E.O. (2000) ${ }^{13}$ C-Detected ${ }^{1}$ H Spin Diffusion and ${ }^{1}$ H Relaxation Study of Multicomponent Polymer Blends. Macromolecules, 33, 115-119.

[14] Tavares, M.I.B. (2000) NMR Molecular Dynamic Study of High Crystalline Polymers. Polymer Testing, 19, $899-904$. http://dx.doi.org/10.1016/S0142-9418(99)00060-4

[15] Nogueira, M.C.J.A., Tavares, M.I.B. and Nogueira, J.S. (2004) ${ }^{13}$ C NMR Molecular Dynamic Investigation of Tropical Wood Angelin Pedra (Hymenolobium paetrum). Polymer, 45, 1217-1222. http://dx.doi.org/10.1016/j.polymer.2003.12.031

[16] Nogueira, R.F., Tavares, M.I.B. and San Gil, R.A.S. (2004) Carbon-13 Solid State NMR Study of Polypropylene/Clay Nanocomposite. Journal of Metastable and Nanocrystalline Materials, 22, 71-76. http://dx.doi.org/10.4028/www.scientific.net/JMNM.22.71

[17] Tavares, M.I.B, Nogueira, R.F., San Gil, R.A.S., Preto, M., Silva, E.O., Silva, M.B.R. and Miguez, E. (2007) Polypropylene-Clay Nanocomposite Structure Probed by H NMR Relaxometry. Polymer Testing, 26, 1100-1102. http://dx.doi.org/10.1016/j.polymertesting.2007.07.012

[18] Monteiro, M.S.S.B., Silva, E.O., Rodrigues, C.L., Cucinelli Neto, R.P. and Tavares, M.I.B. (2012) The Structure of Polycaprolactone-Clay Nanocomposites Investigated by ${ }_{1} \mathrm{H}$ NMR Relaxometry. Journal of Nanoscience and Nanotechnology, 12, 7307-7313. http://dx.doi.org/10.1166/jnn.2012.6431

[19] Passos, A.A., Tavares, M.I.B., Cucinelli Neto, R.P., Moreira, L.A. and Ferreira, A.G. (2011) Preparation of EVA/Silica Nanocomposites Characterized with Solid State Nuclear Magnetic Resonance. Polímeros, 21, 98-102. http://dx.doi.org/10.1590/S0104-14282011005000023

[20] Olejniczak, S., Kaźmierski, S., Pallathadka, P.K. and Potrzebowski, M.J. (2007) A Review on Advances of High-Resolution Solid State NMR Spectroscopy in Structural Studies of Polymer/Clay Nanocomposites. Polimery, 52, 713-792.

[21] Soares, I.L., Chimanowsky, J.P., Luetkmeyer, L., Silva, E.O., Souza, D.H.S. and Tavares, M.I.B. (2015) Evaluation of the Influence of Modified $\mathrm{TiO}_{2}$ Particles on Polypropylene Composites. Journal of Nanoscience and Nanotechnology, 15, 5723-5732. http://dx.doi.org/10.1166/jnn.2015.10041 